\title{
Quality of life for type II diabetes mellitus patients in a suburban tertiary hospital in Thailand
}

\author{
Chankawee Komaratat
}

Clinical Research Center, Faculty of Medicine, Thammasat University, Pathumthani, Thailand

Naruemon Auemaneekul

Department of Public Health Nursing, Faculty of Public Health, Mahidol University, Bangkok, Thailand, and

Wirin Kittipichai

Department of Family Health, Faculty of Public Health, Mahidol University, Bangkok, Thailand

\begin{abstract}
Purpose - The purposes of this paper were to assess the quality of life (QoL) in patients with type II diabetes mellitus (DM) in a suburban tertiary hospital and determine the factors that affect the QoL including individual characteristics, health factors, self-care behaviors and social support.

Design/methodology/approach - This study was a cross-sectional study among DM type II cases being treated in a suburban tertiary hospital in Thailand. Data were collected by personal interview from 188 patients in 2018. Diabetes-39 was administered to assess QoL.

Findings -54.3 percent of patients had good QoL. Total score of QoL was moderate which found an average score of $216.0 \pm 41.0,46.8 \%$ had moderate level in self-care behaviors and 56.4 percent had moderate level in social support. The factors associated with QoL in patients were cerebrovascular disease (Fisher $=7.2$, $p=0.01)$, self-care behaviors $(r \mathrm{~s}=0.191, p=0.008)$ and social support $(r \mathrm{~s}=0.229, p=0.002)$.

Originality/value - Health care system ought to develop a policy driven to improve the QoL in DM type II patients by encouraging self-care behaviors and social support for DM type II patients.

Keywords PRECEDE, Quality of life, Self-care behaviors, Social support, Type II diabetes mellitus patients, Thailand

Paper type Research paper

\section{Introduction}

Diabetes mellitus (DM) is a chronic illness and a major public health challenge. In 2015, 8.8\% of the global population aged $20-79$ years had DM, and $90 \%$ of cases suffered from the type II category [1]. In Thailand, a survey in 2012 found that newly registered cases of DM totaled 336,265 cases, representing an incidence of 523 per 100,000 of the population with numbers increasing. The population over 60 years has the highest prevalence of $\mathrm{DM}$, and the central region of Thailand has the highest prevalence followed by the northeast, north and southern regions respectively [2]. Inadequate control of blood sugar can result in adverse complications

(C) Chankawee Komaratat, Naruemon Auemaneekul and Wirin Kittipichai. Published in the Journal of Health Research. Published by Emerald Publishing Limited. This article is published under the Creative Commons Attribution (CC BY 4.0) license. Anyone may reproduce, distribute, translate and create derivative works of this article (for both commercial and non-commercial purposes), subject to full attribution to the original publication and authors. The full terms of this license may be seen at http:// creativecommons.org/licences/by/4.0/legalcode

The authors wish to thank the department of Medicine, Thammasat University Hospital, the staff and all participants. This study was partly supported for publication by the Department of Public Health Nursing and Faculty of Public Health, Mahidol University, Bangkok, Thailand.
\end{abstract}

Received 14 May 2019 Revised 4 September 2019 30 October 2019 Accepted 4 December 2019
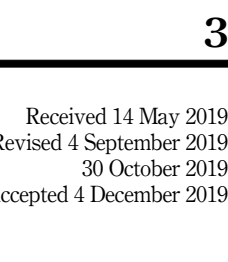

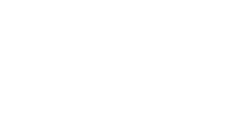

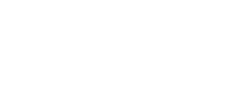

(n) 
JHR

35,1

of the diseases [1]. Complications from DM involving the eyes account for $2.6 \%$ cases who are blind. Regarding the effects of complications of kidney function related to DM, a study of 54 countries found that $80 \%$ of chronic kidney disease cases were attributed to DM. DM cases with foot lesions are at high risk of amputation. There is a 20 -fold increased risk of amputation of an infected for DM cases [2]. Therefore, DM is a major cause of death and disability causing significant harm to a nation's economy and a person's quality of life (QoL) [1]. Previous research confirmed that DM with complications significantly reduced QoL [3] while other studies found QoL in patients with type II DM were moderate and low [4-6].

In Thailand, the provision and facilitation of healthy activity programs in rural areas where the community is more united are far more intact. In rural areas, health care systems and activities are run by a health-promoting hospital which works with community health volunteers. In urban areas such as Bangkok, the public health center's strong health care system is provided by the Bangkok metropolitan authority. However, people living in suburban areas are mostly neglected as their geographical area is often unclear and sometimes overlaps between the urban and rural areas. Moreover, suburban areas are often inaccessible with the majority of the community remaining isolated. Therefore, when comparing urban and rural health care systems, there are many barriers to accessing the health care system and healthy activities in the suburban area. Addressing known factors associated with QoL in patients with DM type II in suburban areas is therefore necessary. The result would be useful to develop proper intervention and guidelines for improving the $\mathrm{QOL}$ among patients with type II DM in suburban tertiary hospitals.

Based on the PRECEDE framework of Green and Kreuter [7], the researcher found the variable from previous research regarding the factors most associated with QoL in DM patients include health factors (BMI) [6], HbA1c test results [8], duration of illness [3, 4, 8], complications of DM $[3,5,9,10]$ and severity of DM complications, especially cerebrovascular disease [11], self-care behaviors [12] (e.g. nutrition, physical activity and exercise, taking medicine, blood sugar self-assessment, self-care to reduce complications and managing emotion and psychological state), environmental factors which encompass social support [5, 13] (e.g. information support, emotional support, appraisal support, moral support,and instrumental support including money, material, labor, services), individual characteristics including gender [6, 10, 14], age [4,9], occupation [5], marital status [3], income [5, 6, 9] and education $[5,10,14]$. However, there is still lack of studies focusing on the direct association among behaviors and social environment and QoL. Therefore, in this study, the researcher applied the PRECEDE framework of Green and Kreuter in phase 2 epidemiology, behavioral and environment assessment to study the association between behaviors, health factors and environmental factors in assessing the QoL of type II DM patients.

The objectives of this study were to assess the QoL in patients with type II DM in a suburban tertiary hospital and to analyze the relationship between individual characteristics (e.g. gender, age, occupation, marital status, education and income), health factors (e.g. BMI, $\mathrm{HbA1c}$, duration of illness, complications and underlying disease), self-care behaviors, social support and QoL in patients with type II DM.

\section{Methods}

This research was a cross-sectional study among DM type II cases being treated at the diabetes clinic of the internal medicine unit of the Thammasat University Hospital in Pathum Thani Province near Bangkok.

The sample size was calculated using the means and standard deviation of a known population, as adapted from Konsantiya's [6] study of DM type II cases in Muangyang Hospital, Nakhon Ratchasima. The mean was 3.65 and standard deviation was 0.35 , yielding a prescribed sample size of 186 cases. 
The questionnaire for this research had five sections:

(1) Individual characteristics (age, gender, occupation, marital status, education and income)

(2) Health factors (BMI, HbA1c, duration of illness, complications status, cerebrovascular status, Diabetes Complications Severity Index (DCSI)

(3) A 27- item self-care behaviors questionnaire (based on the American Diabetes Association [15]; sub-concept composed of self-care in nutrition, physical activity exercise, taking medicine, blood sugar self-monitoring, blood sugar self-assessment, self-care to reduce risk of complications and self-care in managing emotion and psychological state)

(4) A 20-item social support questionnaire (based on Caplan [16] and House [17]) with a sub-concept composed of emotional support, moral support, appraisal support, instrumental support and information support) and

(5) A 39-item quality of life assessment (Thai short version) for Diabetes-39 (D-39) (translated to Thai by Songraksa and Leukiatbundhit [18] based on Boyer [19] with sub-concepts composed of sexual functioning dimension, diabetes control dimension, anxiety dimension, social burden dimension, energy and mobility dimension and health problem dimension)

Grouping scores were based on Bloom [20] as $\geq 80=$ Good, 60-79 = Fair, < 60 = Inappropriate. The questionnaire was tested for content validity by two experts in nursing and a public health professor. The draft questionnaire was pretested for reliability with a group of $30 \mathrm{DM}$ type II cases being treated at the hospital, and the results were tested using Cronbach's alpha coefficient. The results from the pretesting phase were that the value for self-care behaviors was 0.76, social support was 0.91 and QoL assessment was 0.93. The sample was selected from the medical records of the hospital.

The criteria for inclusion in the study were patients enrolled in the diabetes clinic of the internal medicine unit of the Thammasat University Hospital with DM type II disease for at least one year, age 27-84 years old, ability to communicate in Thai and voluntary agreement to participate in the study by written consent.

Data were collected by personal interview (conducted by the researcher and a trained researcher assistant) from February to April 2018. Data were analyzed using descriptive statistics, chi-square, and Fisher's exact test for variables (gender, occupation, marital status, education, grouping income, complications status, cerebrovascular status) and Spearman's rho, with statistical significance set at $p<0.05$ for variables with interval to ratio scale (age, BMI, HbA1c, duration of illness, DCSI score, self-care behaviors and sub-concept of self-care behaviors and social support and sub-concept of social support).

\section{Ethical consideration}

The research protocol and survey instrument were approved by the Thammasat University ethical review board, faculty of medicine (Project No. MTU-EC-RS-0-212/60).

\section{Results}

Descriptive statistics

As shown in Table 1, most of the sample were female, aged between 27 and 84 years (mean of 63.6) with one-third (35.1\%) over 69 years. Remaining ratios were $60-69$ years $(32.4 \%), 50-59$ years $(18.6 \%)$ and under age $50(13.8 \%)$. Most of the samples were not currently employed. Around $71.3 \%$ were married. One-third $(35.1 \%)$ had completed a bachelor's degree of
Type II diabletes mellitus and quality of life 
JHR

35,1

Characteristics and health factors

$n(\%)$

Gender

Male

Female

$112(59.6)$

Age (years)

$\leq 60$

$76(40.4)$

6

$>60$

67 (35.6)

$121(64.4)$

Occupation

Retired/out of work

$115(61.2)$

Currently employed

$73(38.8)$

Marital status

Single

Couple

$54(28.7)$

134 (71.3)

Education

Primary school or lower

$62(33.0)$

Secondary education or diploma

$60(31.9)$

Bachelor's or higher degree

66 (35.1)

Income (per month/ THB)

$<5,000$

55 (29.3)

$5,000-15,000$

$39(20.7)$

$15,001-30,000$

$52(27.7)$

$>30,000$

$42(22.3)$

BMI $\left(\mathrm{kg} / \mathrm{m}^{2}\right)$

Underweight $<18.5$

$8(4.3)$

Normal 18.5-22.9

$39(20.7)$

Overweight 23.0-27.5

$39(20.7)$

Obesity $\geq 27.5$

$102(54.3)$

Min $=13.2, \max =43.7$, mean $\pm \mathrm{SD}=26.1 \pm 4.8$

$\mathrm{HbA1c}$

$\mathrm{HbA1c}<7 \%$

$114(61.3)$

Min $=4.5, \max =17$, mean $\pm \mathrm{SD}=7.6 \pm 1.6$

$49(26.1)$

Duration of illness (year)

1-5

$58(30.9)$

6-10

$60(31.9)$

$>20$

$21(11.1)$

$\operatorname{Min}=1, \max =40$, mean $\pm \mathrm{SD}=11.8 \pm 1$

$55(29.3)$

With complications

$45(70.3)$

Number of complications

1

$34(18.1)$

$16(8.5)$

2
3

Numbers and

No cerebrovascular

$5(2.7)$

With cerebrovascular

$8(4.3)$

characteristics and health factors 


\section{Characteristics and health factors}

Diabetes complications severity index (DCSI score) $(n=188)$

DCSI score $=0$

DCSI score $=1$

DCSI score $=2$

DCSI score $=3$

DCSI score $>3$

Min $=0, \max =5$, mean $\pm \mathrm{SD}=0.58 \pm 1.1$

Underlying disease (U/D) $(n=188)$

Yes (Alternative choices) (Top 10)

1 Hypertension

2 Hyperlipidemia

3 Cataract

4 Heart diseases

5 Rheumatoid

6 Anemia

7 CKD

8 Fatty liver

9 Cholesterolaemia

10 Thalassemia

11 Cerebrovascular diseases

12 Thyroid

13 Asthma
133 (70.7)

25 (13.3)

14 (7.4)

9 (4.8)

7 (3.7)

$165(87.8)$

$136(72.3)$

46 (24.5)

19 (10.1)

17 (9.0)

14 (7.4)

$13(6.9)$

12 (6.4)

$11(5.9)$

11 (5.9)

9 (4.8)

8 (4.3)

8 (4.3)

8 (4.3)

Note(s): Abbreviations: HbA1c = Hemoglobin A1c; BMI = Body Mass Index; CKD = Chronic Kidney Disease

Table 1.

education or higher, while $31.9 \%$ had high school or diploma education, and $33.0 \%$ were educated below high school level. $29.3 \%$ of the sample had a monthly income of less than 5,000 baht, followed by $15,001-30,000$ baht $(27.7 \%)$, over 30,000 baht $(22.3 \%)$ or $5,000-15,000$ baht $(20.7 \%)$.

The BMI of the sample was $13.2-43.7 \mathrm{~kg} . / \mathrm{m}^{2}$ with an average BMI of $26.1 \pm 4.8 \mathrm{~kg} . \mathrm{m}^{2}$. $\mathrm{HbA} 1 \mathrm{c}$ levels were $4.5-17 \%$ with the average $\mathrm{HbA1c}$ at $7.6 \pm 1.6 \%$. The duration of diabetesrelated illness was between $1-40$ years. The average time was $11.8+8.2$ years. Most $(31.9 \%)$ of the sample was aged between 11-20 years. The majority of the sample had only 1 complication (18.1\%). The majority of the sample had no cerebrovascular disease $(95.7 \%)$. Most of the sample had DCSI scores of 0 points $(70.7 \%) .87 .8 \%$ had other chronic underlying diseases. The most chronic underlying disease was hypertension $(72.3 \%)$ followed by hyperlipidemia $(24.5 \%)$ and cataract $(10.1 \%)$.

As shown in Table $246.8 \%$ practiced "moderate" self-care followed by $45.7 \%$ who had "poor" self-care and 7.4\% who practiced "good" self-care. The majority of the sample practiced good self-care in taking medicine $(83.0 \%)$ while the lowest self-care score was selfmonitoring of blood sugar (2.1\%).

As shown in Table 3, most (56.4\%) of the sample had "moderate" social support, followed by $22.9 \%$ with "good" social support and $20.7 \%$ with "poor" social support. The majority of the sample had good emotional support (50.5\%), followed by informational support (41.5\%) and moral support $(29.3 \%)$, while the lowest social support category was instrumental support $(17.6 \%)$.

Table 4 presented numbers and proportions of the sample and the QoL level. Most of the sample had a good QoL (54.3\%). For each dimension of QoL, the result found that the majority of the sample had good QoL in the energy and mobility dimension $(77.1 \%)$, followed by the 
JHR 35,1

8 sexual functioning dimension $(76.6 \%)$ and social burden dimension $(57.4 \%)$, while the lowest QoL was in the health problem dimension (38.3\%).

\section{Factors associated with QoL in DM type II}

Table 5 and Table 6 show that factors associated with QoL in patients with DM type II at Thammasat University Hospital were cerebrovascular disease. Dimension of self-care behaviors with significant positives associated with QoL included taking medicine $\left(r_{\mathrm{s}}=0.241, p=0.001\right)$, self-care to reduce risk of complications $\left(r_{\mathrm{s}}=0.218, p=0.003\right)$ and self-care to control one's emotions $\left(r_{\mathrm{s}}=0.288, p=0.002\right)$. However, the result revealed that self-monitoring of blood sugar had a significant negative association with QoL $\left(r_{\mathrm{s}}=-0.197\right.$, $p=0.007)$. Dimensions of social support that had positive association with QoL were emotional support $\left(r_{\mathrm{S}}=0.202, p=0.005\right)$, moral support $\left(r_{\mathrm{s}}=0.185, p=0.011\right)$ and appraisal support $\left(r_{\mathrm{S}}=0.179, p=0.014\right)$.

\begin{tabular}{lccc}
\hline Self-care behaviors & Good $n(\%)$ & Moderate $n(\%)$ & Poor $n(\%)$ \\
\hline Nutrition & $64(34)$ & $92(48.9)$ & $32(17.0)$ \\
Physical activity exercise & $14(7.4)$ & $21(11.2)$ & $153(81.4)$ \\
Taking medicine & $156(83.0)$ & $22(11.7)$ & $10(5.3)$ \\
Blood sugar self-monitoring & $4(2.1)$ & $6(3.2)$ & $178(94.7)$ \\
Blood sugar self-assessment & $35(18.6)$ & $42(22.3)$ & $111(59.0)$ \\
Self-care to reduce complications & $42(22.3)$ & $62(33.0)$ & $84(44.7)$ \\
Managing emotion and psychological state & $58(30.9)$ & $52(27.7)$ & $78(41.5)$ \\
Overall self-care behaviors & $14(7.4)$ & $88(46.8)$ & $86(45.7)$ \\
Max $=121$, min $=68$, mean $=93, \mathrm{SD}= \pm 13$ & & &
\end{tabular}

Table 2.

Numbers and proportions of the sample and self-care behaviors

\begin{tabular}{lcrr}
\hline Social support & Good $n(\%)$ & Moderate $n(\%)$ & Poor $n(\%)$ \\
\hline Emotional support & $95(50.5)$ & $72(38.3)$ & $21(11.2)$ \\
Informational support & $78(41.5)$ & $66(35.1)$ & $44(23.4)$ \\
Instrumental support & $33(17.6)$ & $52(27.7)$ & $103(54.8)$ \\
Appraisal support & $45(23.9)$ & $78(41.5)$ & $65(34.6)$ \\
Moral support & $55(29.3)$ & $82(43.6)$ & $51(27.1)$ \\
Overall social support & $43(22.9)$ & $106(56.4)$ & $39(20.7)$ \\
Max $=100$, min $=44$, mean $=76, \mathrm{SD}= \pm 11$ & & & \\
\hline
\end{tabular}

Table 4.

Numbers and proportions of sample and quality of life

\begin{tabular}{lrcc}
\hline Quality of life & Good $n(\%)$ & Moderate $n(\%)$ & Poor $n(\%)$ \\
\hline Sexual functioning dimension & $144(76.6)$ & $19(10.1)$ & $25(13.3)$ \\
Diabetes control dimension & $85(45.2)$ & $53(28.2)$ & $50(26.6)$ \\
Anxiety dimension & $92(48.9)$ & $56(29.8)$ & $40(21.3)$ \\
Social burden dimension & $108(57.4)$ & $36(19.1)$ & $44(23.4)$ \\
Energy and mobility dimension & $145(77.1)$ & $26(13.8)$ & $17(9.0)$ \\
Health problem dimension & $72(38.3)$ & $53(28.2)$ & $63(33.5)$ \\
Overall quality of life & $102(54.3)$ & $46(24.5)$ & $40(21.3)$ \\
Max $=$ 237, min $=102$, mean $=216, \mathrm{SD}= \pm 41$ & & & \\
\end{tabular}




\begin{tabular}{|c|c|c|c|c|c|c|}
\hline Characteristics & Good $n(\%)$ & $\begin{array}{l}\text { Quality of life } \\
\text { Moderate } n(\%)\end{array}$ & Poor $n(\%)$ & \multicolumn{2}{|c|}{ Sig. } & $\begin{array}{r}1 \text { ype } 11 \\
\text { diabletes }\end{array}$ \\
\hline \multicolumn{4}{|l|}{ Gender } & \multirow[t]{3}{*}{$\chi^{2}=1.06$} & \multirow[t]{3}{*}{0.58} & mellitus and \\
\hline Male & $39(38.2)$ & $18(39.1)$ & $19(47.5)$ & & & quality of life \\
\hline Female & $63(61.8)$ & $28(60.9)$ & $21(52.5)$ & & & \\
\hline Occupation & & & & \multirow{3}{*}{$\chi^{2}=4.57$} & \multirow[t]{3}{*}{0.12} & \\
\hline Retired/out of work & $67(65.7)$ & $22(47.8)$ & $26(65.0)$ & & & $\mathbf{a}$ \\
\hline Employment & $35(34.3)$ & $24(52.2)$ & $14(35.0)$ & & & \\
\hline Marital status & & & & \multirow[t]{3}{*}{$\chi^{2}=2.36$} & \multirow[t]{3}{*}{0.29} & \\
\hline Single & 28 (27.5) & $17(37)$ & $9(22.5)$ & & & \\
\hline Couple & $74(72.5)$ & $29(63)$ & $31(77.5)$ & & & \\
\hline Education & & & & \multirow[t]{5}{*}{$\chi^{2}=11.95$} & \multirow[t]{5}{*}{0.06} & \\
\hline Primary school or lower & 34 (33.3) & 19 (41.3) & $8(20.0)$ & & & \\
\hline Secondary education & $27(26.5)$ & $8(17.4)$ & $8(20.0)$ & & & \\
\hline Diploma & $12(11.8)$ & $3(6.5)$ & $2(5.0)$ & & & \\
\hline Bachelor's or higher degree & $29(28.4)$ & $16(34.8)$ & $22(55.0)$ & & & \\
\hline Income (per month/THB) & & & $22(30.0)$ & \multirow{5}{*}{$\chi^{2}=3.17$} & \multirow[t]{5}{*}{0.79} & \\
\hline$<5,000$ & $33(32.4)$ & $12(26.1)$ & $10(25.0)$ & & & \\
\hline $5,000-15,000$ & $22(21.6)$ & $11(23.9)$ & $6(15.0)$ & & & \\
\hline $15,001-30,000$ & $27(26.5)$ & $13(28.3)$ & $12(30.0)$ & & & \\
\hline$>30,000$ & $20(19.5)$ & $10(21.7)$ & $12(30.0)$ & & & \\
\hline Age (years) & & & & \multirow{3}{*}{$r_{\mathrm{s}}=-0.11$} & \multirow[t]{3}{*}{0.12} & \\
\hline$\leq 60$ & $33(32.4)$ & $16(34.8)$ & $18(45.0)$ & & & \\
\hline$>60$ & $69(67.6)$ & $30(65.1)$ & $22(55.0)$ & & & \\
\hline Health factors & Good $n(\%)$ & $\begin{array}{l}\text { Quality of life } \\
\text { Moderate } n(\%)\end{array}$ & Poor $n(\%)$ & \multicolumn{2}{|l|}{ Sig. } & \\
\hline No complications & $73(71.6)$ & $36(76.1)$ & $24(60.0)$ & $\gamma^{2}=2.84$ & 0.24 & \\
\hline With complications & $28(28.4)$ & $11(23.9)$ & $16(40.0)$ & & & \\
\hline Underlying diseases (U/D) & & & & $\chi^{2}=1.1$ & 0.99 & \\
\hline No U/D & $12(11.8)$ & $5(10.9)$ & $6(15.0)$ & & & \\
\hline 1 Disease & $26(25.5)$ & $13(28.3)$ & $10(25.0)$ & & & \\
\hline 2 Diseases & $34(33.3)$ & $13(28.3)$ & $11(27.5)$ & & & \\
\hline 3 Diseases & $18(17.6)$ & $9(19.6)$ & $8(20.0)$ & & & \\
\hline More than 3 diseases & $12(11.8)$ & $6(13.0)$ & $5(12.5)$ & & & \\
\hline No cerebrovascular & $101(99.0)$ & $41(89.2)$ & 38 (95) & Fisher $=7.2$ & $0.01 *$ & \\
\hline With cerebrovascular & $1(1.0)$ & $5(10.8)$ & $2(5)$ & & & \\
\hline$B M I\left(k g . / m^{2}\right)$ & & & & $r_{\mathrm{s}}=0.06$ & 0.37 & \\
\hline Underweight & $3(2.9)$ & $1(2.2)$ & $4(10.0)$ & & & \\
\hline Normal & $20(19.6)$ & $11(23.9)$ & $8(20.0)$ & & & \\
\hline Overweight & $22(21.6)$ & $10(21.7)$ & $7(17.5)$ & & & \\
\hline Obesity & $57(55.9)$ & $24(52.2)$ & $21(52.5)$ & & & \\
\hline$H b A 1 c$ & & & & $r_{\mathrm{s}}=0.06$ & 0.41 & \\
\hline $\mathrm{HbA} 1 \mathrm{c}<7 \%$ & $53(64.6)$ & 27 (67.5) & $21(61.8)$ & & & \\
\hline $\mathrm{HbAlc} \geq 7 \%$ & $29(35.4)$ & $13(32.5)$ & $13(38.2)$ & & & \\
\hline Duration of illness (years) & & & & $r_{\mathrm{s}}=0.004$ & 0.95 & \\
\hline $1-5$ & $24(23.5)$ & $13(28.3)$ & $12(30.0)$ & & & \\
\hline $6-10$ & $33(32.4)$ & $12(26.1)$ & $13(32.5)$ & & & \\
\hline $11-20$ & 35 (34.3) & $15(32.6)$ & $10(25.0)$ & & & \\
\hline$>20$ & $10(9.8)$ & $6(13.0)$ & $5(12.5)$ & & & \\
\hline DCSI scores & & & & $r_{\mathrm{s}}=-0.06$ & 0.39 & \\
\hline DCSI score $=0$ & $72(70.6)$ & 35 (76.1) & $26(65.0)$ & & & \\
\hline DCSI score $=1$ & $13(12.7)$ & $6(13.0)$ & $6(15.0)$ & & & \\
\hline DCSI score $=2$ & $9(8.8)$ & $4(8.7)$ & $1(2.5)$ & & & \\
\hline DCSI score $=3$ & $6(5.9)$ & $1(2.2)$ & $2(5.0)$ & & & \\
\hline DCSI score $>3$ & $2(2.0)$ & $0(0.0)$ & $5(12.5)$ & & & Table 5 \\
\hline $\begin{array}{l}\text { Note(s): Abbreviations: Bl } \\
\text { Severity Index }\end{array}$ & $=$ Body Mass I & lex; HbAlc = Hemo & obin A1c; DCSI & $=$ Diabetes Comp & ations & $\begin{array}{l}\text { Factors associated } \\
\text { with quality of life }\end{array}$ \\
\hline
\end{tabular}




\begin{tabular}{|c|c|c|c|}
\hline & & & \\
\hline $\begin{array}{l}\mathrm{JHR} \\
351\end{array}$ & Factors associated with QoL & $r_{\mathrm{s}}$ & Sig \\
\hline & Self-care behaviors & 0.191 & $0.008^{* * *}$ \\
\hline & 1. Nutrition & 0.029 & 0.69 \\
\hline & 2. Physical activity exercise & -0.007 & 0.92 \\
\hline & 3. Taking medicine & 0.241 & $0.001 * *$ \\
\hline & 4. Blood sugar self-monitoring & -0.197 & $0.007 * *$ \\
\hline 10 & 5. Blood sugar self-assessment & 0.066 & 0.368 \\
\hline & 6. Self-care to reduce risk of complications & 0.218 & $0.003 * *$ \\
\hline & 7. Managing emotion and psychological state & 0.288 & $0.002 * *$ \\
\hline & Social support & 0.229 & $0.002 * *$ \\
\hline & 1. Emotional support & 0.202 & $0.005^{* *}$ \\
\hline & 2. Moral support & 0.185 & $0.011 *$ \\
\hline $\begin{array}{l}\text { I able b. } \\
\text { Spearman rank }\end{array}$ & 3. Appraisal support & 0.179 & $0.014 *$ \\
\hline $\begin{array}{l}\text { Spearman rank } \\
\text { correlation coefficient }\end{array}$ & 4. Instrumental support & 0.100 & 0.172 \\
\hline of factors associated & 5. Information support & 0.124 & 0.09 \\
\hline with quality of life & Note(s): ${ }^{*} p$-value $<0.05,{ }^{* *} p$-value $<0.01$ & & \\
\hline
\end{tabular}

\section{Discussion}

Based on the findings, slightly over half (54.3\%) of the sample had "good" QoL, while one-fifth $(21.3 \%)$ had "poor" QoL. The total score of QoL was moderate. Respondents reported satisfactory QoL for their sexual functioning and energy and mobility. QoL was only moderate for the dimensions of diabetes control, anxiety, social burden and health problems. These findings are consistent with the research of Changchuea [5], Srichaijaroonpong et al. [4] and Konsantiya [6] who also studied QoL of diabetes cases in Angthong, Sakon Nakorn and Nakorn Ratchasima provinces and also found that the QoL in patients with DM type II was moderate.

To analyze the QoL of the samples, this research applied the PRECEDE framework of Green and Kreuter [7]. In the analysis stage, epidemiological methods (Phase2) were used to assess individual characteristics, behavior factors, health factors and social environment factors directly affecting QoL of DM type II patients. The focus of this phase is to identify specific health factors and nonhealth factors that are associated with QoL. Individual characteristics such as gender, occupation, marital status, education, income and age were supposed to be associated with self-care behaviors and QoL according to the literature review mentioned earlier. However, the proportion of males and females in this study was not much different from each other (59.6\% and $40.4 \%$ respectively). The analysis found that gender was not related to QoL in this study. This might be because, at present, males and females have equal roles and functions in society, a hypothesis that is consistent with the findings of Changchuea [5] and Srichaijaroonpong et al. [4]. Besides, occupation was not associated with QoL in this study. This is possibly due to the general life satisfaction of the samples where the majority had retired from work $(61.2 \%)$, granting them increased free time for leisure activities compared to those who were employed which normally would have a stress burden from work, which is consistent with the studies of Srichaijaroonpong et al. [4] and Konsantiya [6]. The DM type II in this study was quite homogenous in terms of marital status where more than two-thirds of the sample were couples $(71.3 \%)$. Therefore, the result found no association between marital status and QoL, possibly because people can now live more independently. Besides in the current suburban environment, there are many conveniences to help individuals meet their daily needs. Also, medical care has advanced significantly, which is consistent with the studies of Changchuea [5] and Konsantiya [6]. In this study, education was not a significant predictor of QoL. This may be because modern technology, communication and information enable individuals to find knowledge more easily regardless of their education level. The findings of this study are consistent with the research of 
Srichaijaroonpong et al. [4] and Konsantiya [6]. The monthly income of the sample was not associated with QoL. This is possibly due to the diversity of this sample of DM type II cases. Increasingly, Thais are following the principles of sufficiency economy which holds that you can have a QoL regardless of your income if you live holistically. Conversely, having a lot of money does not prescribe happiness in life if one does not spend wisely. This finding is consistent with the research of Srichaijaroonpong et al. [4]. The majority of DM type II cases in this study were aged 64 years and over $(64.4 \%)$. However, age in this study was not associated with QoL. This is probably because the DM patients in this study were mostly elderly. This is consistent with Changchuea [5] but inconsistent with Srichaijaroonpong et al. [4]. Therefore, correlations between age and QoL in type II DM should be further explored.

Complications of diabetes in this study were not associated with QoL which is not congruent with the PRECEDE framework where health factors could predict QoL. This might be because most patients $(70.3 \%)$ had complications, which is normal for DM type II especially when it becomes a chronic illness. Regarding underlying diseases, our findings are consistent with the research of Changchuea [5] who found that hypertension, cholesterol and obesity were associated with QoL of the DM type II cases. However, this study did find that having a cerebrovascular illness was significantly associated with QoL of the DM type II patients even though samples with cerebrovascular illness was at only $4.3 \%$. This is probably because patients with a cerebrovascular illness have paresis and are unable to take care of themselves resulting in poor QoL. This study further revealed that BMI was not significantly associated with QoL of the DM type II cases. Besides, most DM patients were found to be obese (54.3\%), only a few normal $(20.7 \%)$ and some underweight (4.3\%), therefore causing no relationship between BMI and QoL. HbA1c was also not associated with QoL. This may be because most patients could not control their blood sugar level (61.3\%), and the HbA1c level of each patient did not vary greatly. The duration of illness with diabetes was also not a significant predictor of QoL. Overall, the sample had DM type II for 11 years on average. This finding is consistent with the research of Changchuea [5], Konsantiya [6], Wannachat et al. [9] and Ababio et al. [21]. Regarding DCSI scores, these were not associated with QoL, possibly because a few of the cases had severe levels of complications (3.7\%). Most had DCSI scores of $0(70.7 \%)$.

For the analysis of behavioral factors for QoL in the PRECEDE framework of Green and Kreuter [7], in this study, self-care behaviors of this sample were at a moderate level overall $(46.8 \%)$, with a high level for taking medicine $(83.0 \%)$. However, blood sugar self-monitoring was relatively low (2.1\%). Perhaps this is because the DM cases needed to visit regular clinics for check-ups and felt that the hospital was a better place to detect a problem. Also, difficulties in measuring individual blood sugar were perceived as a burden. This study found a significant association between self-care behaviors and QoL of DM type II. Those with good self-care behaviors showed higher QoL than those with poor self-care $\left(r_{s}=0.191, p<0.01\right)$. The finding is consistent with the research of Watanune [12], and the result could also be supported by the framework of Green and Kreuter [7] who portrayed that behaviors could explain QoL. In this study, most of the self-care behaviors dimensions were positively associated with QoL (e.g. taking medicine, self-care to reduce risk of complications, managing emotion and psychological state). Logically, taking medicine could boost QoL due to the positive treatment effects on illness. Self-monitoring of blood sugar was negatively associated with QoL, perhaps because the sample scored rather low for this behavioral variable. It could be a reverse association because cases with poor blood sugar levels have to monitor themselves more often, and that is seen as a burden. Conversely, those with good blood sugar levels took a blood sugar test when they visited the doctor at a clinic; so they were already experiencing a better QoL. It is impressive that the samples in this study were able to manage their emotions and psychological state to remain optimistic and to decrease anxiety regarding their illness. Cases took advantage of free counseling provided by the DM clinic and that helped them to cope with diabetes.
Type II diabletes mellitus and quality of life 
JHR

35,1

For the analysis of the social environment factors of QoL in the PRECEDE framework of Green and Kreuter [7], in this study, it was found that the majority of DM patients (56.4\%) had a moderate level of social support. Overall, social support was significantly and positively associated with QoL in this study. The result is in line with the framework of Green and Kreuter [7] who mentioned that environment factors encompass social support as a predictor of QoL. It stands to reason that if a case of diabetes still receives emotional warmth and moral support, he/she would practice more self-care behaviors and, in turn, that would boost QoL. This finding is consistent with the study of Changchuea [5]. Social support in the form of emotional support, moral support and appraisal support was significantly correlated with QoL. Clearly, the warmth and love from family and friends had a positive effect on the outlook and health behaviors of the diabetes case, which in turn leads to better QoL. Counseling from a significant other reinforces the sense of being respected and cared for, and this boosts the desire to comply with treatment. There is a greater sense of self-efficacy that comes from improved QoL. Most important, perhaps, is being accepted in mainstream society and having the opportunity to be a productive member of society despite having a chronic condition such as diabetes.

\section{Conclusion}

It was found that most participants had a good level of QoL (54.3\%) followed by moderate level ( $24.5 \%)$ and poor level $(21.3 \%)$. When looking at each dimension of QoL, it was found that the sample had good QoL in the energy and mobility dimension, sexual functioning dimension, social burden dimension, anxiety dimension, diabetes control dimension and health problem dimension. This study found that cerebrovascular disease was significantly related to QoL $(p<0.05)$. Patients with good self-care behaviors have a good QoL. Social support factors of DM type II patients had a positive relationship with QoL with statistical significance $(\phi<0.01)$. DM type II patients who received higher levels of social support had a better QoL than patients who received lower levels of social support. When looking at each dimension, it was found that social support in the form of emotional, moral and instrumental support was correlated with QoL.

\section{Implication for practice and future research}

(1) Implication for practice

A policy drive to increase the level of QoL among DM type II, especially among the elderly with DM type II, should be considered. Giving priority to self-care behaviors and social support could help DM patients to monitor and control sugar levels and prevent cerebrovascular disease which could eventually cause low QoL. Self-care behaviors should focus more on taking medicine, blood sugar self-monitoring, self-care to reduce risk of complications and self-care to managing emotion and psychological state. Even though instrumental support was not a big concern in the suburban context where people have high education and moderate income, social support should emphasize emotional, moral and appraisal support. In doing so, QoL among DM type II would be maximized, increase good health status and decrease the risk of complications.

(2) Implication for future research

The sample size should be more generalized for future research with the relationship between age and QoL explored in more detail. Intervention focusing on self-care behaviors and social support could help DM type II patients to develop a better QoL. Moreover, more qualitative research on QoL dimensions among the elderly with DM type II living in suburban 
areas would provide in-depth information to help understand, increase and maintain QoL over time.

\section{References}

1. International Diabetes Federation [IDF]. IDF diabetes atlas 2015 update. 7th ed. Brussels, Belgium: IDF; 2015.

2. Kanchanapiboonwong A. Annual epidemiological surveillance report 2012. [updated: 2012; cited 2017 June 4]. Available at: http://www.boe.moph.go.th/Annual/AESR2012/main/AESR55_Part1/ file11/5955_Diabetes.pdf.

3. Pragodpol P, Suwannaka Y, Chairit A. Quality of life in chronic disease patients with and without complications and guidelines for improving the quality of life. Nonthaburi: Health Systems Research Institute; 2015.

4. Srichaijaroonpong S, Inthasoi T, Petchwisai A, Paisan R. Factors relating to the quality of life of the diabetic patients at Ban Chiang Kruea Pho Chai health promoting hospital Chiang Kruea sub district Muang district Sakon Nakorn province. Journal of the office of DPC 7 Khon Kaen. 2016; 23(3): 23-33. (in Thai).

5. Changchuea W. Quality of life of diabetic patients in Sawaeng Ha district, Ang Thong province. Region 4 Medical Journal. 2013; 15(2): 97-104. (in Thai).

6. Konsantiya S. Quality of life of diabetic mellitus persons: a case study at Muangyang Hospital Nakhonratchasima. The Journal of Boromarajonani College of Nursing, Nakhon Ratchasima. 2011; 17(1): 31-44. (in Thai).

7. Green LW, Kreuter MW. Health promotion planning: an educational and ecological approach. 4th ed. New York: McGraw-Hill; 2005.

8. Heepkaew S, Laohasiriwong W. Quality of life of patients with type II diabetes mellitus in Kuchinarai district, Kalasin province. Research and Development Health System Journal. 2011; 4(1): 22-36. (in Thai).

9. Wannachart M, Nanthamongkolchai S, Munsawaengsub C, Taechaboonsermsak P. Quality of life among elderly people with chronic diseases in Ubon Ratchathani province. J. Publ. Health. 2015; (Special issue): 18-29. (in Thai).

10. Safita N, Islam SM, Chow CK, Niessen L, Lechner A, Holle R, et al. The impact of type 2 diabetes on health related quality of life in Bangladesh: results from a matched study comparing treated cases with non-diabetic controls. Health Qual Life Outcomes. 2016 Sep; 14(1): 129. doi: 10.1186/ s12955-016-0530-7.

11. Pho-ngam D. The comparison of quality of life between diabetes-related toe amputees and diabetes- related below knee amputees. Srinagarind Medical Journal. 2016; 31(1): 8-15. (in Thai).

12. Wattanune $\mathrm{N}$. The factors influencing to health-related quality of life amongst the patients with congestive heart failure at a community in Kanchanaburi province. Bangkok: Christian University of Thailand; 2012.

13. Muksiritipanun B, Monthaisong D. Factors related to quality of life in patients with diabetic retinopathy. Journal of the Royal Thai Army Nurses. 2014; 15(2): 395-404. (in Thai).

14. Javanbakht M, Abolhasani F, Mashayekhi A, Baradaran HR, Jahangiri noudeh Y. Health related quality of life in patients with type 2 diabetes mellitus in Iran: a national survey. PloS One. 2012; 7(8): e44526. doi: 10.1371/journal.pone.0044526.

15. American Diabetes Association. General diabetes information and AADE self-care behaviors. [cited 2017 November 20]. Available at: http://peersforprogress.org/wp-content/uploads/2012/05/ 20130509_peers_for_progress_general_diabetes_information.pdf.

16. Caplan G. Support systems and community mental health. New York: Behavioral Publication; 1974.

17. House JS. Work stress and social support. Reading, MA: Addison- Wesley; 1981. 
JHR

35,1

14

18. Songraksa K, Lerkiatbundit S. Development of a disease specific quality of life instrument: Thai version of the Diabetic-39. Songklanakarind Medical Journal. 2009; 27(1): 35-49. (in Thai).

19. Boyer JG, Earp JA. The development of an instrument for assessing the quality of life of people with diabetes. Diabetes-39. Medical Care. 1997 May; 35(5): 440-53. doi: 10.1097/00005650199705000-00003.

20. Bloom B S. Learning for mastery: evaluation comment. Center for the study of instruction program. Los Angeles: University of California; 1986.

21. Ababio GK, Bosomprah S, Olumide A, Aperkor N, Aimakhu C, Oteng-Yeboah A, Agama J, Chaplin WF, Okuyemi KS, Amoah AGB, Ogedegbe G., Predictors of quality of life in patients with diabetes mellitus in two tertiary health institutions in Ghana and Nigeria. Niger Postgrad Med J. 2017 Jan-Mar; 24(1): 48-55. doi: 10.4103/npmj.npmj_3_17.

\section{Corresponding author}

Naruemon Auemaneekul can be contacted at: naruemon.aue@mahidol.ac.th

For instructions on how to order reprints of this article, please visit our website:

www.emeraldgrouppublishing.com/licensing/reprints.htm

Or contact us for further details: permissions@emeraldinsight.com 